\title{
Radicular cyst or Odontogenic keratocyst? : A case report
}

\author{
Dr. Shruti Bohra ${ }^{1}$, Dr. Rohan Bhede ${ }^{2}$, Dr. Hrushikesh Saraf ${ }^{3}$, \\ Dr. Minal Chaudhary ${ }^{4}$, Dr. Nisu Swastika ${ }^{5}$, Dr. Alka Hande ${ }^{6}$ \\ 1,2,3,4,5,6 (Department of Oral Pathology \& Microbiology, SPDC, DMIMSU, Sawangi, Wardha, Maharashtra, \\ India).
}

\begin{abstract}
Inflammatory jaw cysts comprise a group of lesions that arise as a result of epithelial proliferation within an inflammatory focus due to a number of causes. Radicular cysts are the most common inflammatory cysts. These cysts are found most commonly at the apices of the involved teeth. These cysts are seldom very large and very rarely cross the midline. There has been a review for Odontogenic keratocyst that it may grow to a very large size before it manifests clinically. Large size of OKC contributes to one of the reasons for considering it as a cystic neoplasm. In the present case, size of the cyst was enormous which was confusing which on histological examination was confirmed as a radicular cyst.
\end{abstract}

Keywords: Anachoresis, Large radicular cyst, Mimicking lesions, Odontogenic Keratocyst

\section{Introduction}

Correct treatment begins with correct diagnosis. Arriving at a correct diagnosis require knowledge skill and art. Because many diseases have similar symptoms, the clinician must be astate in determining the correct diagnosis [1]. One lesion mimicking the other poses the diagnostic dilemma. According to Brannon odontogenic keratocyst mostly occur in ramus of mandible while radicular cysts are universal in occurrence. [2] This case report serves a dual purpose firstly it is a documentation of a large radicular cyst which is rare in literature secondly it implies the importance of mimicking lesions which can severely change our treatment planning.

\section{Case report:}

A fifty five year old male patient reported to the department of conservative dentistry and endodontic with chief complains of mobility of teeth in lower anterior region of jaw, pain with teeth in lower right and left posterior region of jaw since fifteen days. On examination, 31 was discolored, Grade one mobility was seen with 45,46 and 34, 35. Draining sinus was seen in relation to 45. (Fig. A)

\section{Investigations:}

3.1) Orthopantomogram revealed generalized interdental alveolar crestal bone resorption. Radiopaque coronal restoration was seen with 16, 17 and 26. A single large well defined radiolucency seen in lower anterior region of jaw approximately of size $7.5 \mathrm{~cm} \times 3.5 \mathrm{~cm}$ extending supero-inferiorly from periapical region of $41 \& 31$ to $0.5 \mathrm{~cm}$ above lower border of mandible and anterioposteriorly from mesial of 46 to distal of 36 with scalloped margin causing root resorption with 46,45 and 36,35 . (Fig. B)

3.2) Pulp Vitality Test was done for all the teeth. It revealed that 46, 45, 44, 43, 42, 41, 31, 32, 33, 34,35 were nonvital.

\section{Treatment Advised:}

Root Canal Treatment with all nonvital teeth. (Fig. C)

Under aseptic conditions local anesthesia ( $2 \%$ xylocaine) was delivered. Conventional access opening was done followed by Biomechanical preparation; using Protaper NiTi rotary system. Irrigation was done with $3 \%$ of sodium hypochlorite \& $2 \%$ Chlorhexidine. Obturation was done using lateral condensation method. Finally all the root canal treated teeth were restored using glass ionomer cement.

4.2) Surgical management: (Fig. D)

Under all aseptic conditions standard patient preparation was done. Under general anesthesia nasotracheal intubation was done. Crevicular incision was given extending from 36 to 46 , full thickness mucoperisteal flap was raised, bone exposed, cystic lining was seen in the same region. Enucleation of the cystic lining was done, followed by chemical curettage with the help of Carnouys solution. Cystic lining was sent for pathological examination. Cystic space was then cleaned with betadine soaked gauze piece and closure of the flap was done with the help of 3-0 vicryl suture material. 
(Fig. E, F \& G)

\section{Histological examination}

The specimen was sent for histological examination.

Fig E shows grossed specimens which were then processed and histopathological slides were prepared.

Fig $\mathrm{F}$ shows scanner view of cystic cavity lined by proliferative epithelium with underlying fibro-cellular connective tissue stroma. Epithelium shows arcading pattern peculiar for radicular cyst.

Fig G shows high power view of cholesterol clefts and few multinucleated giant cells in one section on the tissue.

Final diagnosis: Radicular cyst

\section{Discussion}

Kramer in 1974 has defined a cyst as a pathological cavity having fluid, semifluid or gaseous contents and which is not created by accumulation of pus. In the present case the size of radicular cyst was very large and hence it was confused with odontogenic keratocyst for final diagnosis. An apical cyst (pocket or true) is classified as an inflammatory and not a neoplastic lesion in the WHO Histological Typing of Odontogenic Tumors, Jaw Cysts, and Allied Lesions and OKC is classified as a cyst of developmental origin.[3] Unlike epithelial cells of an odontogenic keratocyst, which is a neoplastic lesion, the basal cells of an inflammatory apical cyst are not capable of self-proliferation without stimulation by external signals such as inflammatory mediators, proinflammatory cytokines, and growth factors released by innate and adaptive immune cells during apical periodontitis. [4, 5]

In this case it was very peculiar that no apparent cause other then endodontically involved anterior teeth were evident for the formation of the radicular cyst. The infection might have started with mandibular anterior teeth. Periapical periodontitis is a local response of bone around the apex of the tooth that develops after necrosis of the pulp tissue or extensive periodontal disease apical infections may spread and produce symptoms when the bacteria becomes stronger than the host's defense systems.[6, 7] This concept may contribute to the large size of the cyst.

There is a phenomenon called anachoresis which has been investigated to explain the presence of microorganisms in unexposed dental pulps. Bacteria introduced into the gingival sulcus or bloodstream can be recovered in teeth with pulp inflammation [8]. It attributes to the destruction of the pulp vessels and the increased vascular permeability resulting from inflammation [9] This might explain the involvement of $34,35,44,45,46$ endodontically other than anteriors as no other pathology was clinically seen.

Persistence of Inflammatory Apical Cysts after Nonsurgical Root Canal Therapy Lesions associated with apical periodontitis such as granulomas, abscesses, and cysts fail to heal after nonsurgical root canal therapy because of extraradicular infection. It is well-established that root canal infection is the cause of primary and post-treatment apical periodontitis. [10,11] Besides inflammatory apical true cysts, cholesterol crystals have been suggested as a possible cause that prevents healing of apical periodontal lesions. Especially in inflammatory apical true cysts, after nonsurgical root canal therapy healing does not occur because macrophages are thought to be the cause which are not able to engulf and digest cholesterol crystals [12].

Accumulation of cholesterol crystals in an apical periodontitis lesion can prevent post-endodontic healing of periapical tissue. Because these agents exist outside the root canal system, endodontic retreatment is unlikely to resolve the factors that sustain the post-therapeutic periapical lesion. Therefore, apical surgery is indicated for successful treatment of such cases [13]. It is also widely believed in the endodontic community and described in several endodontic textbooks that large cyst-like periapical lesions and apical true cysts are most likely not able to heal by nonsurgical root canal therapy alone. $[14,15,16]$

\section{Treatment of the radicular cyst:}

There are three treatment options for all periapical periodontitis (radicular cyst, periapical granuloma, and periapical abscess): nonsurgical endodontic therapy, surgical endodontic therapy, and extraction. Large lesions may need to be treated with endodontic therapy combined with a biopsy or marsupialization, decompression, or fenestration [17]. Out of the mentioned we opted for enucleation because the advantage of enucleation is the immediate rehabilitation resulting in fewer control appointments, which makes it a good choice for patients with poor compliance [18]. 


\section{Figures}

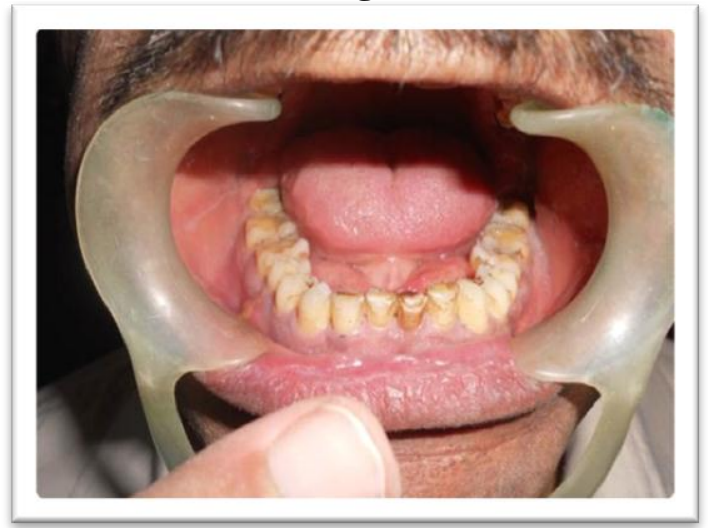

Figure A (Intra-oral-preoperative)

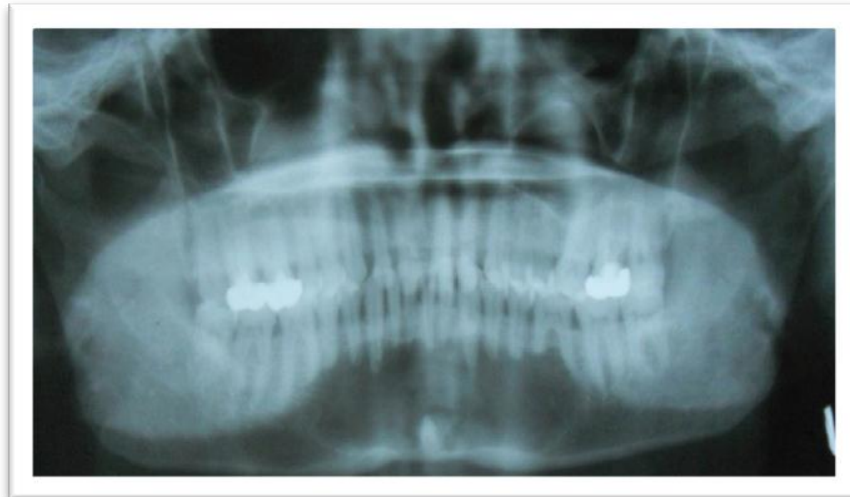

Figure B (Preoperative OPG)

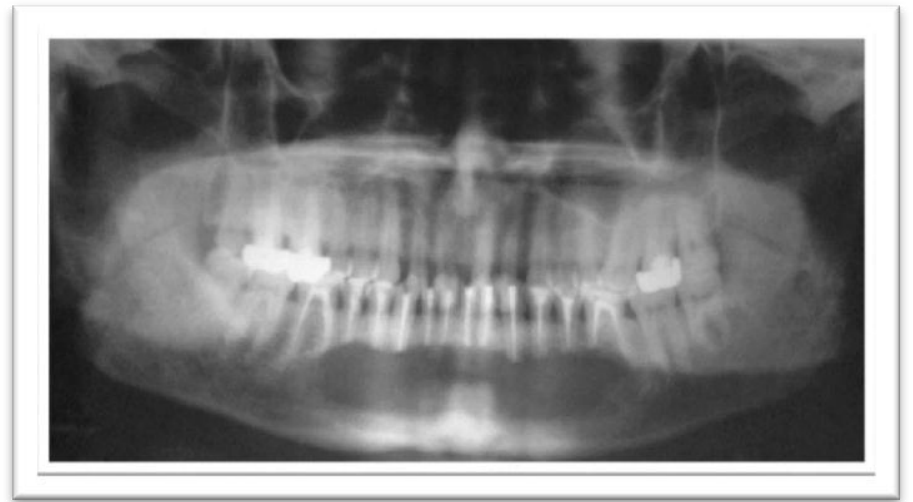

Figure C (OPG after endodontic treatment)

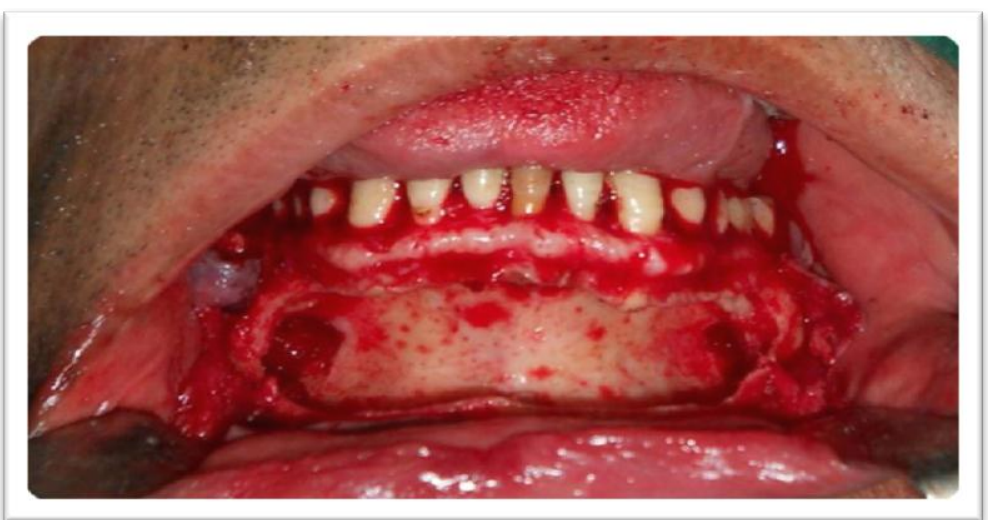

Figure D (Surgical management) 


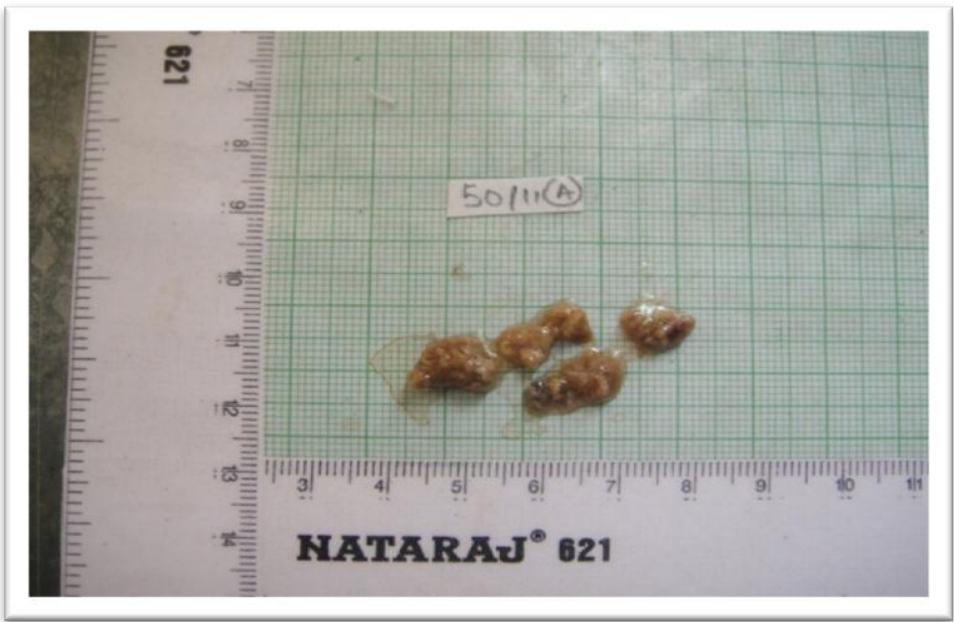

Figure E (Grossed Specimen)

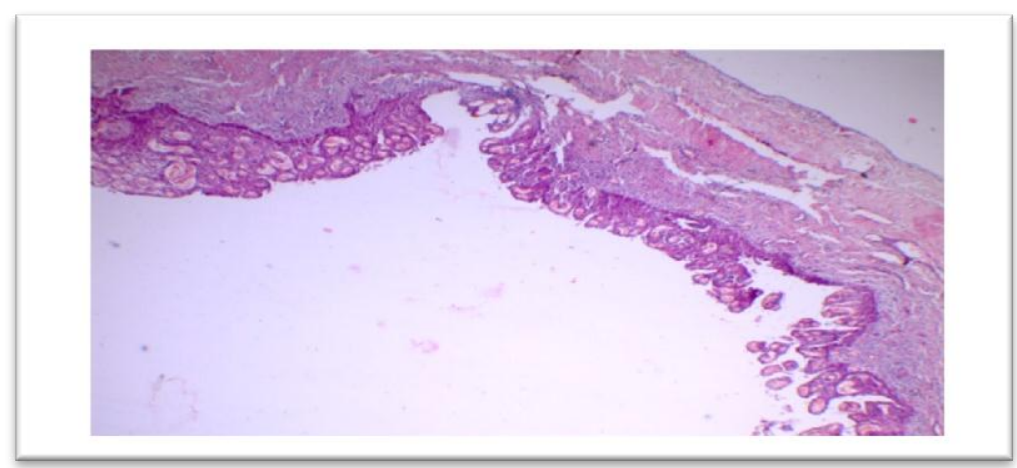

Figure F (Histopathological picture)

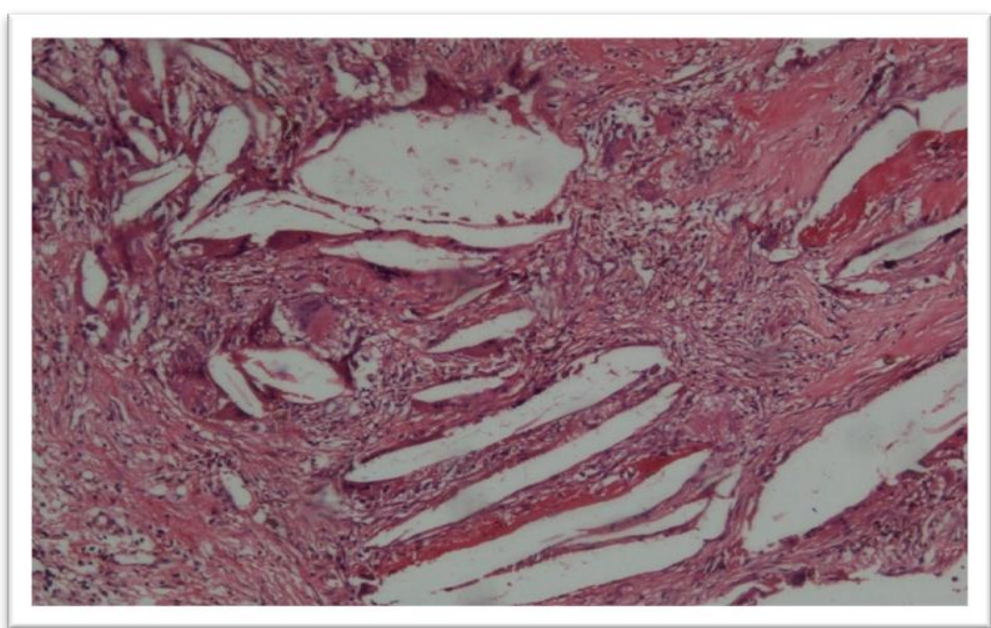

Figure G (Histopathological picture)

\section{Conclusion}

The large radicular cyst is an osseous disease of endodontic origin that on radiographic examination can look like odontogenic keratocyst. Since the documentation of such large radicular cyst is rare, caution is required in the establishment of the diagnosis to avoid unnecessary bone cutting and extraction of teeth.

\section{References}

[1]. L. I. Grossman, S. Oliet, C. E. Del Rio, Endodontic Practice, Lea and Febiger, Philadelphia, USA, $11^{\text {th }}$ edition, 1988.

[2]. W. G. Shafer, M. K. Hine, and B. M. Levy, A Textbook of Oral Pathology, WB Saunders, Philadelphia, Pa, USA, $4^{\text {th }}$ edition, 1983.

[3]. D. M. G. Main, "Epithelial jaw cysts: 10 years of WHO classification," J Oral Pathol Med, vol. 14, pp. 1-7, 1985.

[4]. D. C. Barreto, R. S. Gomez, A. E. Bale, W. L. Boson, L. De Marco, "PTCH gene mutations inOdontogenic keratocysts," J Dent Res, vol. 79, pp. 1418-1422, 2000. 
[5]. L. M. Lin, G. T. Huang, P. A. Rosenberg, "Proliferation of epithelial cell rests, formation of apical cysts, and regression of apical cysts after periapical wound healing,”J Endod, vol. 33, pp. 908-916, 2007.

[6]. B. Demiralp, H. G. Keceli, M. Muhtarogullan, et al, "Treatment of periapical inflammatory lesion with the combination of plateletrich plasma and tricalcium phosphate," J Endod, vol. 30, pp. 796-800, 2004

[7]. P. Stashenko, C-Y. Wang, N. Tani-Ishii, S. M. Yu, "Pathogenesis of induced rat periapical lesions," Oral Surg Oral Med Oral Pathol, vol. 78, pp. 494-502, 1994.

[8]. L. I. Grossman, "Origin of microorganisms in traumatized, pulpless, sound teeth," J Dent Res, vol. 46, pp. 551-553. 1967.

[9]. D. Tziafas, "Experimental bacterial anachoresis in dog dental pulps capped with calcium hydroxide," J Endod, vol. 15, pp. 591-595, 1989.

[10]. S. Kakehashi, H. Stanley, R. Fitzgerald, "The effect of surgical exposures of dental pulps in germ-free and conventional laboratory rats," Oral Surg Oral Med Oral Pathol, vol. 20, pp. 340-349, 1965.

[11]. P. N. R. Nair, U. Sjogren, K. E. Kahnberg, G. Krey, G. Sundqvist, "Intraradicular bacteria and fungi in root-filled, asymptomatic human teeth with therapy-resistant periapical lesions: a long-term light and electron microscopic follow-up study," J Endod, vol. 16, pp. 580-588, 1990

[12]. P. N. R. Nair, "Cholesterol as an aetiological agent in endodontic failures: a review," Aust Endod J, vol. 25, pp. 19-26. 1999.

[13]. L. M. Louis, R. Domenico, L. Jarshen, R. A. Paul, "Nonsurgical Root Canal Therapy of Inflammatory Periapical Lesions and Apical Cysts," J Endod, vol. 35, pp. 607-615, 2009

[14]. J. Ingle, L. Bakland, C. Baugartner, Ingle's endodontics. St Louis: Saunders, $6^{\text {th }}$ edition, 2009

[15]. E. Natkin, R. J. Oswald, L. I. Carnes, "The relationship of lesion size to diagnosis, incidence and treatment of periapical cysts and granulomas," Oral Surg, vol. 57, pp. 82-94, 1984.

[16]. P. N. R. Nair, "New perspectives on radicular cysts: do they heal," Int Endod J, vol. 31, pp. 155-160, 1998

[17]. H. Hemalatha, G. Neerav, K. Yogesh, K. Sadanand, Y. S. Shoeb, S. Metgud, "Single-step Apical Barrier Placement in Immature Teeth Using Mineral Trioxide Aggregate and Management of Periapical Inflammatory Lesion Using Platelet-rich Plasma and Hydroxyapatite," J Endod, vol. 34, pp. 1020-1024, 2008.

[18]. M. Giuliani, G. B. Grossi, C. Lajolo, M. Bisceglia, K. E. Herb, "Conservative management of a large odontogenic keratocyst: report of a case and review of the literature," J Oral Maxillofac Surg, vol. 64, pp.308-316, 2006. 